\title{
Direct Determination of Air Density in a Balance Through Artifacts Characterized in an Evacuated Weighing Chamber.
}

\author{
W. F. Koch \\ Center for Analytical Chemistry, National Bureau of Standards, Washington, DC 20234 \\ R. S. Davis and V. E. Bower \\ Center for Absolute Physical Quantities, National Bureau of Standards, Washington, DC 20234 \\ June 29, 1978

\begin{abstract}
This paper describes a simple device which permits mass comparisons in air without appeal to the correction for air buoyancy. The device consists of a canister which is evacuated and weighed on a laboratory balance with a mass inside. A second weighing of another mass in the evacuated canister provides the desired mass comparison. The method was used to determine the mass difference between two stainless steel weights of widely differing densities. With knowledge of this mass difference and of the volume difference one may, by a simple air weighing of the two objects, determine directly the density of the air in the balance case. Densities of air determined by this method were compared with those calculated from the barometric pressure, the temperature, and the relative humidity of the laboratory air. The experimental and calculated values agree throughout to within $1.0 \mu \mathrm{g} \mathrm{cm}^{-3}$ (where the normal air density is about $1.2 \mathrm{mg} \mathrm{cm}{ }^{-3}$ ). The calculated and experimental values of day-to-day fluctuations in air density agree to within $0.5 \mu \mathrm{g} \mathrm{cm}^{-3}$.
\end{abstract}

Key words: Buoyancy of air; density; mass comparisons in vacuo; precise weighing; vacuum; vacuum weighing.

\section{Introduction}

In recent years, the authors have participated in two separate electrochemical studies of the Faraday constant. Koch and Diehl made a determination of the Faraday by the coulometric titration of a base, 4-aminopyridine [1]; ${ }^{1}$ Bower and Davis have made a series of determinations by the anodic dissolution of high-purity silver into perchloric acid solution [2]. Both of these measurements were designed to provide values of the Faraday constant with uncertainties of about one ppm. A constant of such accuracy might make a contribution toward the resolution of the discrepancy between the values for the Faraday obtained directly (electrochemically) and indirectly (by calculation from accurately known physical constants). For details on this last point the reader is referred to Taylor et al. [3], and Cohen and Taylor [4].

The accuracy of an electrochemical measurement can be no greater than that of the associated mass measurements. The uncertainty in the definition and transfer of the electrical units into the Faraday laboratory in the Electrical Measurements and Standards Division, National Bureau of Standards

\footnotetext{
${ }^{1}$ Figures in brackets indicate literature references at the end of this paper.
}

(NBS) is believed to be no greater than $0.3 \mathrm{ppm}$ with respect to the NBS maintained units. To keep to 1-2 ppm the uncertainty of the measurement of the Faraday constant, the mass measurements, with all their corrections, must have an uncertainty of no greater than about $0.9 \mathrm{ppm}$, irrespective of the materials used.

Of the various corrections to be applied to mass determination, such as those for the sensitivity of the balance, the calibration of the standard weights, etc., the correction for the air buoyancy appears as the least amenable to direct determination. For the buoyancy correction, one almost always relies on a calculation of air density by some algorithm whose entries are such laboratory observables as the barometric pressure, the temperature, the relative humidity and, sometimes, the carbon dioxide content of the air.

The general question of the limits of validity of the various closely related air density algorithms advanced in the scientific literature and the question of the direct precise determination of air density in a balance chamber are matters of considerable moment at present to the metrological community. The urgency of these questions, among others, led the Bureau International des Poids et Mesures to hold a meeting on precision mass determinations in November 1976 at Sèvres, France [5]. 
Our study was undertaken with the aim of making direct, accurate measurement of the air density in order to confirm the air density algorithm which we used in computing the buoyancy corrections to the mass determinations required for the Faraday experiments.

\section{The Problem and the Method}

The evaluation of the buoyancy correction to weighings of 4-aminopyridine, aqueous solutions and other low-density materials offers some difficulties if one uses high-density (platinum or stainless steel) standards. The density of 4aminopyridine is about $1.27 \mathrm{~g} \mathrm{~cm}^{-3}$. The weight standards are made of stainless steel, density about $8 \mathrm{~g} \mathrm{~cm}^{-3}$. For an uncertainty of only $1 \mathrm{ppm}$ in the mass of 4-aminopyridine or aqueous solutions, the density of air, about $0.0012 \mathrm{~g} \mathrm{~cm}^{-3}$ at room temperature, must be known with an uncertainty no greater than 0.08 percent.

We have made a direct physical determination of the air density in a balance chamber and have compared the results with the version of the algorithm which is given below. The experimental method, based on Archimedes' principle, has been used successfully before, notably by Baxter [6] who used a globe to determine his buoyancy corrections, and by Jaquerod and Borel [7], who weighed a float in various samples of air under standard conditions in order to obtain the variation in density. To this end we have employed stainless steel artifacts to permit direct measurement of density of air in a balance. We have been anticipated in the use of this principle in recent years by Bowman et al. [8] and by Bruhlmans and Eschbach [9].

We have furthermore employed a method of determining the mass of these objects by comparisons in vacuo. Rather than using the expensive, but perhaps more accurate, method of placing a balance in an evacuable enclosure, we have constructed an evacuable enclosure which may be weighed on a chemist's analytical balance.

Let $M_{H}$ and $M_{S}$ be the nearly equal masses of a hollow, low density weight and a solid, high density weight, respectively. Let the respective exterior volumes be $V_{H}$ and $V_{S}$. Let. $M_{H}$ and $M_{S}$ be weighed, successively, within an evacuated enclosure of mass $M_{E}$ and exterior volume $V_{E}$. Calling the air density $\rho$, we have the force equation:

$$
g\left(M_{E}+M_{H}-\rho V_{E}\right)=\left(M_{E}+M_{S}-\rho V_{E}+\Delta M\right) g
$$

where $\Delta M$ represents the small difference indicated on the optical scale of the balance, calibrated with platinum weights, and $g$ represents the local acceleration of gravity. Providing $V_{E}$ and $\rho$ are constant throughout the procedure, the mass difference, $\Delta M=M_{H}-M_{S}$ has been obtained without appeal to an air buoyancy calculation.

Once thus characterized, the two masses $M_{H}$ and $M_{S}$, if their mean densities are sufficiently different, may be used to determine the density of the air in a balance case. If $m$ is the difference in air weight (divided by $g$ ) between $M_{H}$ and $M_{S}$, and if $\Delta V=V_{H}-V_{S}$,

$$
\begin{aligned}
m & =\left(M_{S}-\rho V_{S}\right)-\left(M_{H}-\rho V_{H}\right), \text { or } \\
\rho & =(\Delta M+m) / \Delta V .
\end{aligned}
$$

The values of $\rho$ so obtained may be compared to those calculated from the atmospheric observables.

The vacuum chamber is a stainless steel tube (fig. 1) with one end capped. To the other end is attached a stainless steel flange with a groove in which is set an O-ring whose profile extends slightly above the groove. A separate flat stainless-steel cover with a stainless-steel vacuum valve welded to it reposes on the O-ring. A circular land on the underside keeps the cover centered on the cylindrical chamber. To the vacuum valve is welded a smooth stainless steel tube which serves to attach the whole chamber to a port on a pumping station. Removal of excess material from the valve enabled us to keep the mass of the whole assembly, with a 17 -g weight inside, within the 100 -g capacity of our balance.

The principal dimensions of the apparatus are approximately as follows: length, bottom to flange, $85 \mathrm{~mm}$; inside diameter of chamber, $27 \mathrm{~mm}$; outside diameter of chamber, $29 \mathrm{~mm}$; outside diameter of flange and lid, $33 \mathrm{~mm}$; overall height $127 \mathrm{~mm}$.

Two weights (fig. 1) were constructed of stainless steel, one hollow, the other solid. The hollow weight was constructed by capping stainless steel tubing, $0.25 \mathrm{~mm}$ thick and $25 \mathrm{~mm}$ in diameter with stainless steel sheet $1 \mathrm{~mm}$ thick.

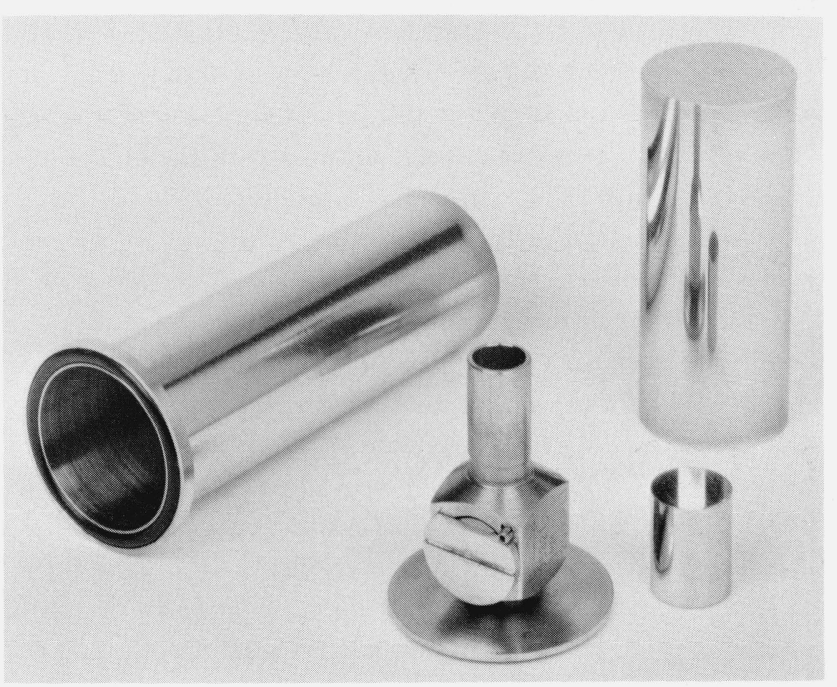

FIGURE 1. Vacuum weighing device consisting of a stainless steel canister and cover with vacuum valve.

The low-density and high-density weights for determining density of air in a balance chamber appear at right. 
The joinings were electron-beam welded and machined smooth, and the object was polished to a specular finish. The result was a weight in the form of a right circular cylinder 50 $\mathrm{mm}$ long, $25 \mathrm{~mm}$ in diameter and weighing about $17 \mathrm{~g}$ (for ultimate use in a 20 -gram capacity microbalance). The cylinder has an overall density of about $0.5 \mathrm{~g} \mathrm{~cm}^{-3}$. The solid weight, a counter-weight to the hollow weight, was constructed from stainless steel bar stock $12 \mathrm{~mm}$ in diameter and is about $18 \mathrm{~mm}$ long. This weight was also given a mirror finish and during the polishing its mass was adjusted to be close to that of the hollow weight. The density of the solid weight is about $8 \mathrm{~g} \mathrm{~cm}^{-3}$.

Mass comparisons with the vacuum chamber were made on a commercial single-pan balance with air damping and optical scale. This balance had a capacity of $100 \mathrm{~g}$ and a resolution of $10 \mu \mathrm{g}$. The air weighings of the two artifacts for checking the adequacy of the algorithm were all made on single-pan instruments with optical scale. These instruments all had a capacity of $20 \mathrm{~g}$, and a resolution of $1 \mu \mathrm{g}$.

Humidity was measured by a simple psychrometer consisting of a wet bulb and a dry bulb thermometer, readable to $0.1{ }^{\circ} \mathrm{C}$, ventilated by an electronic chassis fan. From the readings of this apparatus converted through Ferrels' tables [11] one obtains relative humidity or its equivalent as a term in the air density algorithm. The relative humity so obtained was compared to that indicated by a Dunmore-type electric hygrometer, calibrated at NBS. The two methods yielded values which showed a standard deviation from one another of less than one relative humidity percent. Such an undertainty at 50 percent relative humidity is equivalent to an uncertainty of about 0.02 percent of the air density or about $0.2 \mu \mathrm{g} \mathrm{cm}^{-3}$.

Throughout the comparison of mass and volume of the two artifacts runs the assumption that the volume of the hollow cylinder is constant near atmospheric pressure and that the volume of the chamber is constant when evacuated. The hollow weight has a permanent vacuum inside and the chamber is only weighed when evacuated. Shell and plate theory calculations [12] for the hollow cylinder indicate at worst a $30 \mathrm{ppm}$ volume change as the pressure outside the cylinder varies from zero pressure to about one standard atmosphere. This is equivalent to about a $3 \mathrm{ppm}$ variation in volume over the pressure range normally experienced in the Faraday laboratory at NBS. For the vacuum chamber, which is made somewhat more robust, these considerations hold $a$ fortiori.

The comparison of the masses of the two objects may be briefly described. One of the objects is placed in the vacuum chamber and the chamber is pumped down to an internal pressure of $15 \mathrm{~Pa}(\sim 100$ mtorr) at which point the mass of air left in the chamber is about $10 \mu \mathrm{g}$, the resolution of our balance. The valve is closed and disconnected from the pump. The weight of the ensemble is compared against standard weights of stainless steel in the balance. All weighings are by double substitution with platinum sensitivity weights. After the weighing, the chamber is connected to a source of dry nitrogen and is opened. The next object in the series is substituted for its mate in the chamber and the process is repeated. Weighings were carried out about $600 \mathrm{~s}$ after the evacuation in each instance. Therefore about $900 \mathrm{~s}$ elapsed between weighings. This period seemed to suffice for the dissipation of thermal gradients brought on by expansion of air through the valve hole and by handling. Further delay did not improve the precision.

\section{Results}

Table 1 shows a typical sequence of weighings of the evacuated chamber containing, successively, the hollow weight, the solid weight, and some platinum foil weights

TABLE 1

Successive weighings of evacuated chamber with artifact inside. Weighings were made at 15 minute intervals.

\begin{tabular}{|c|c|c|c|}
\hline $\begin{array}{l}\text { Weighing Se- } \\
\text { quence }\end{array}$ & Platinum (g) & $\begin{array}{l}\text { Solid Stainless } \\
\text { steel }(\mathrm{g})\end{array}$ & $\begin{array}{c}\text { Hollow Stainless } \\
\text { steel (g) }\end{array}$ \\
\hline 1 & 94.56442 & \multirow{4}{*}{94.58228} & \multirow{7}{*}{94.60929} \\
\hline 2 & & & \\
\hline 3 & 94.56433 & & \\
\hline 4 & & & \\
\hline 5 & 94.56435 & \multirow{4}{*}{94.58233} & \\
\hline 6 & & & \\
\hline 7 & 94.56446 & & \\
\hline 8 & & & \multirow[t]{2}{*}{94.60937} \\
\hline 9 & 94.56446 & \multirow{4}{*}{94.58236} & \\
\hline 10 & & & \multirow{5}{*}{94.60942} \\
\hline 11 & 94.56444 & & \\
\hline 12 & & & \\
\hline 13 & 94.56451 & \multirow{5}{*}{94.58246} & \\
\hline 14 & & & \\
\hline 15 & 94.56453 & & \multirow{3}{*}{94.60943} \\
\hline 16 & & & \\
\hline 17 & 94.56446 & & \\
\hline
\end{tabular}

which we had hoped would provide mass standards for use in vacuum. Figure 2 shows the data graphed. For weighings in vacuum the platinum results show high dispersion about a fitted line $\left(\sigma_{i}=48 \mu \mathrm{g}\right)$, about 3 times the dispersion shown by the stainless steel weights. The slope in figure 2 arises from the slow rise of temperature in the balance case as the series of weighings progresses. The slope may be annulled, if desired, by treating the air as an ideal gas, and applying the correction for the exterior volume of the chamber. The apparent difference in slope is not statistically significant.

The difference in mass of the two stainless steel artifacts was calculated in the following way. 


\section{Successive Weighings Of Evacuated Container With Artifact}
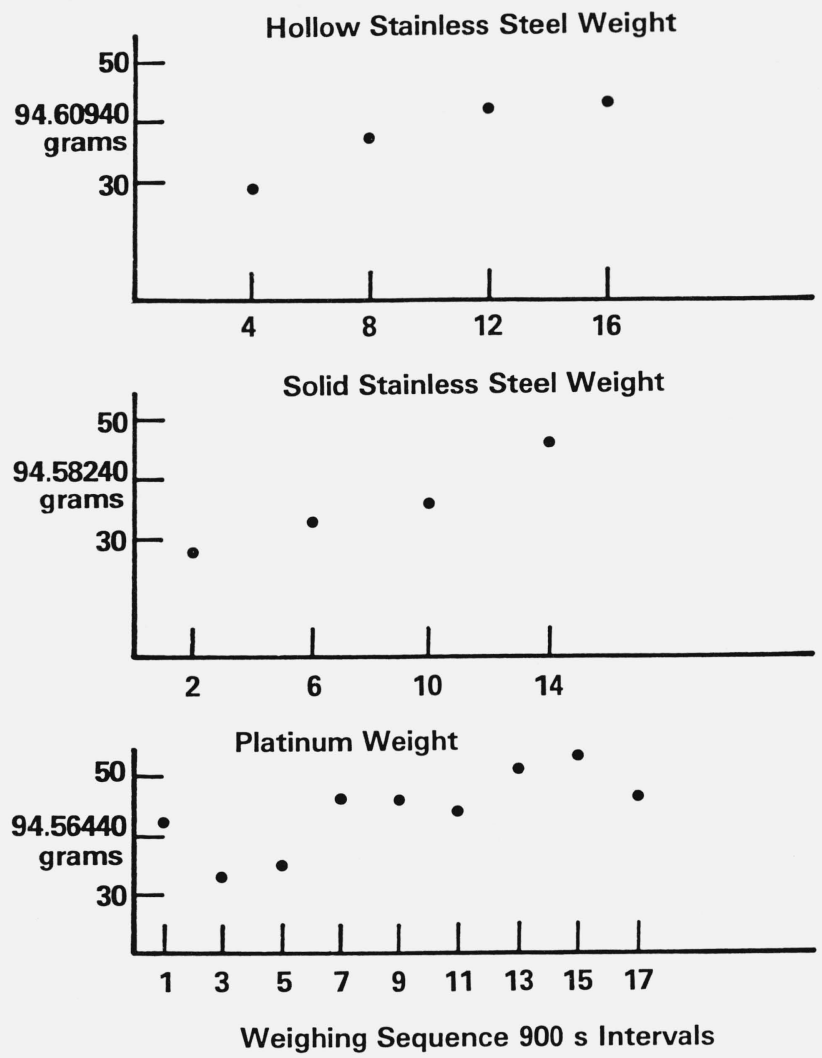

Figure 2. Successive weighings of stainless steel and platinum weights in the evacuated canister.

Straight lines were fitted to the two sets of data and $\sigma_{p p}$, the standard deviation of a predicted point was calculated [10]. We chose the difference between predicted points at a point on the abscissa where the value of $\sigma_{p p}$ is nearly minimum for both sets. The minimum occurs near weighing number 9 . We selected weighing number 9 and calculated the combined $\sigma_{p p}$ value of both sets. Thus

$$
\begin{aligned}
\text { average difference } & =0.02699 \mathrm{~g} \\
\text { combined } \sigma_{p p} & =0.000017 \mathrm{~g}
\end{aligned}
$$

The uncertainty of the difference is thus only slightly larger than the $14 \mu \mathrm{g}$ precision of our 100 gram single-pan balance for a set of two weighings. We shall take $17 \mu \mathrm{g}$ as the uncertainty in the assignment of mass difference of the two artifacts. This quantity will be equivalent to 0.06 percent in the air density.

The volumes of the two artifacts were determined by hydrostatic weighing in an inert fluorocarbon liquid with single-crystal silicon as a volume standard according to the elegant method of Bowman et al. [8].

\section{The Air Density Algorithm - Comparison of Experimental and Calaulated Values.}

A reluctance to accept without scrutiny any of the published air-density algorithms led us to reexamine closely the algorithm used throughout the work reported here and in references [1,2]. We first assume that moist air is composed of two ideal gases: dry air and water vapor. Further, we assume that the mass of moist air in a given volume is simply the sum of the masses of dry air and water vapor as derived from ideal gas behavior. Finally, we account for the nonideal behavior of moist air by introducing a dimensionless multiplicative function, the compressibility factor, which forces our results to agree with the work of Goff and Gratch [13], Hyland [14], and Hyland and Wexler [15] on the thermodynamic properties of moist air. The compressibility factor is nearly constant and differs from 1 by less than 0.05 percent over the ranges of interest.

Although the formulations differ, the assumptions of the algorithm we used are in fact those of the algorithm contained in the Smithsonian Meteorological Tables [16]. The Smithsonian derivation lumps the difference in molecular weight between dry and wet air with the temperature, thereby creating a "virtual temperature." Following this compaction, the derivation again lumps the compressibility factor with the "virtual temperature" to create the "adjusted virtual temperature."

In our formulation, the compressibility factors retain their identity. We calculated the density of air from:

$$
\rho=\frac{\rho_{0} T_{o} C_{d a}(0)}{C(T) P_{0} T}\left[P-e \frac{\left(M_{d a}-M_{w}\right)}{M_{d a}}\right]
$$

where

$$
P=\rho_{\mathrm{Hg}}(O) g(x) l^{*}(O)
$$

and the molar gas constant, $R$, is used in the calculation of $\rho_{o}$, the density of dry air:

$$
\rho_{o}=\frac{M_{d a} P_{o}}{C_{d a}(0) R T_{o}}
$$

In these equations the symbols have the following significance, and values [13], $\rho_{0}$ is the density of dry air; $T_{o}$, the standard temperature, $273.15 \mathrm{~K} ; C_{d a}(O)$, the compressibility factor for dry air at $0{ }^{\circ} \mathrm{C}, 0.9994 ; P_{o}$, the standard pressure, 1013.25 millibars (101325 Pa); $C(T)$, the compressibility factor of moist air at temperature $T, 0.9996$ at $20{ }^{\circ} \mathrm{C}$ and $50 \%$ relative humidity; $T$ is the absolute temperature, $P$ is the pressure in millibars $\left(10^{2} \mathrm{~Pa}\right) ; M_{d a}$ is the effective molecular weight for dry air, $28.966 \mathrm{~g} \mathrm{~mole}^{-1} ; M_{w}$ is the 
molecular weight of water vapor, $18.016 \mathrm{~g} \mathrm{~mole}^{-1}$; and $e$, the saturation vapor pressure of water vapor in millibars, $\left(10^{2}\right.$ $\mathrm{Pa})$. In (3), $\rho_{\mathrm{Hg}}(O)$ is the density of mercury at $0{ }^{\circ} \mathrm{C}, 13.5951$ $\mathrm{g} \mathrm{cm}^{-3} ; g(x)$ is the local acceleration of gravity on the second floor of the Metrology Building, NBS, $980.102 \mathrm{~cm} \mathrm{sec}^{-2}$; and $l^{*}(O)$ is the height in $\mathrm{cm}$ of the barometric mercury column corrected to $0{ }^{\circ} \mathrm{C}$. The value for the molar gas constant was taken from Cohen and Taylor [4].

The two masses were weighed on a 20-g single-pan balance (precision $1 \mu \mathrm{g}$ ). Values for air density in the balance chamber were computed by means of (1). These values were compared to air density values calculated from the air density algorithm using the barometric pressure and relative humidity of the laboratory atmosphere, and the temperature in the balance case. The comparison is listed in table 2.

Also in table 2 are listed determinations of air density which were performed at the National Center for Atmospheric Research Boulder, Colorado, altitude above mean sea level, $1864 \mathrm{~m}$, and the Chemistry Department University of Wyoming, Laramie, altitude $2200 \mathrm{~m}$. The measurements were carried out with balances and barometers similar to those in the Electrical Measurements and Standards Division, NBS, and with our own sensitivity weights and psychrometric apparatus.

The readings taken at Boulder were marred by blustery weather. Also we think that the relative humidity reading may be too high for the conditions prevailing on the date of the measurement. The readings at Laramie were made in an underground laboratory. An unexpected shower occurred sometime during the measurements. However, since no abrupt changes in barometric pressure were observed, we have no reason to suspect the data.

\section{Discussion}

The data in table 2 indicate that once a value for $\Delta M$ is assigned by a vacuum mass comparison (1), the two artifacts will track the air density calculation to within about 0.05 percent of the calculated value. The offset of -0.02 percent is very likely fortuitous, since the uncertainty of the assignment of $\Delta M$, and hence of the offset, is \pm 0.06 percent. Furthermore, the air density algorithm is as valid at high elevations as at NBS, Washington. There is, of course, no reason to expect a change with elevation, but the altitude of the two stations in Colorado and Wyoming is sufficient to show that uncertainties in $\Delta \rho$, table 2 , due to differences in mean atmospheric pressure should be below 0.05 percent for the major metrological laboratories, most of which are lowaltitude stations.

In their paper on high precision density determination, Bowman et al. [8] report results on measurements of air density with hollow and solid weights. The random experimental uncertainty in the results was 0.03 percent to 0.05 percent in the air density in the two separate series. Their measurements are independent of the air density algorithm since the value for $\Delta M$ was determined on a vacuum balance of commercial make [18]. Bowman et al. [8] cite an average value for $\Delta M$ to the nearest microgram but give no error statement on this quantity. If we assume that their uncertainty was $50 \mu \mathrm{g}$, the approximate resolution of the balance used [19], then their experimental uncertainty is about 0.14 percent of the air density.

Toropin and Snegov [20], in an original approach, adjust to identical weight in air an open bulb and a tube, both made of the same glass. The bulb is evacuated and sealed. The two devices now constitute a hollow and a solid weight of density $0.125 \mathrm{~g} \mathrm{~cm}^{-3}$ and $2.0 \mathrm{~g} \mathrm{~cm}^{-3}$ respectively. Toropin and

TABLE 2

Comparison of the density of air, $\rho$, as measured with hollow and solid stainless steel weights, with that calculated from the algorithm.

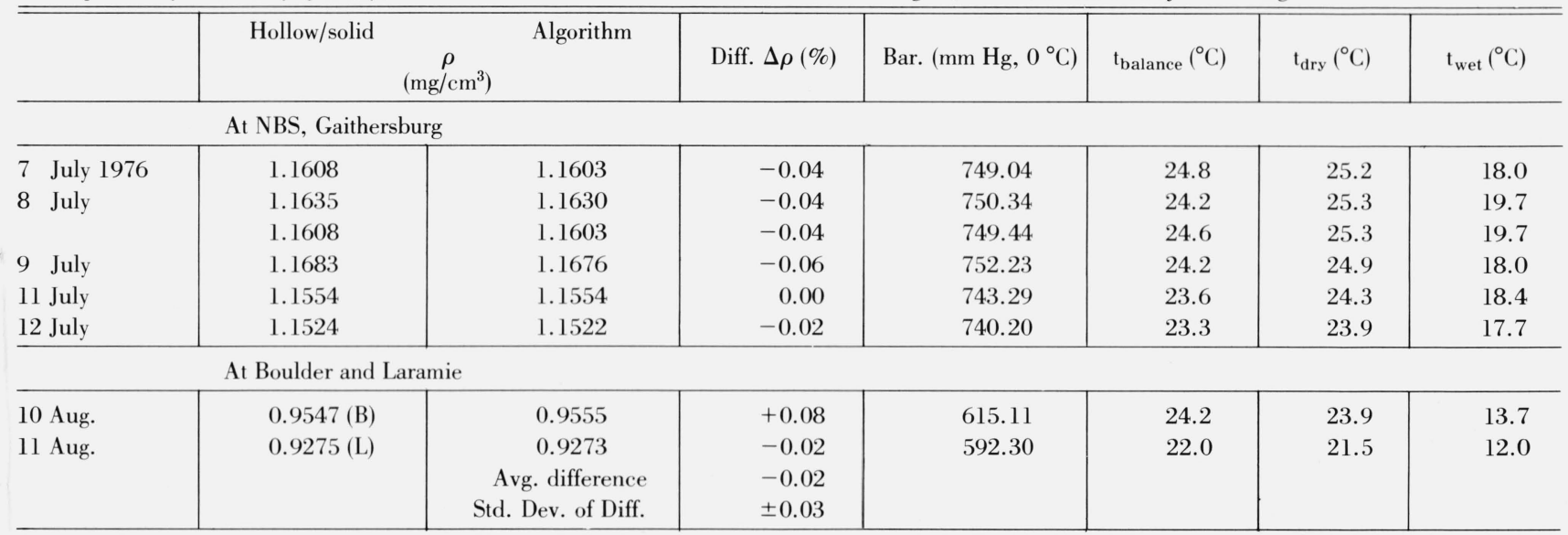


Snegov have therefore made the equivalent of a vacuum weighing. They found an offset of $0.01 \%$ in the density of air with respect to the calculation from their algorithm and a random scatter in $\rho$ of about 0.04 percent, in agreement with the findings of Bowman et al. [8], and with our own.

Jones [17] has recently reformulated an algorithm for calculating the density of air. He concludes from the 300 ppm random uncertainty of his formulation and the $200 \mathrm{ppm}$ systematic uncertainty that the uncertainty of mass transfer from a platinum-iridium to stainless steel kilogram is $30 \mu \mathrm{g}$ random uncertainty and $20 \mu \mathrm{g}$ systematic. Our values would yield by comparison a $70 \mu \mathrm{g}$ overall uncertainty.

Our experimental studies would assign a one standard deviation uncertainty of 0.08 percent to our calculation of the density of air. This amount would lead to uncertainty in assignment of mass values of only $0.08 \mathrm{mg}$ per $100 \mathrm{~cm}^{3}$ difference in volume between objects.

During the experiments we desired to alter the normal properties of the cylinders as little as possible when comparing them in vacuo. It was for this reason that we pumped no lower than $15 \mathrm{~Pa}$. We presume that water absorbed on the stainless steel will be partly removed by the pumping, although a baking would be required to remove all of it, as is shown for stainless steel mass artifacts by Moret [19]. Yoshimori et al. [22] have shown that $0.2-0.7 \mu \mathrm{g}$ of water per $\mathrm{cm}^{2}$ may be removed from the surface of stainless steel weights merely by raising the temperature of the weights to $100{ }^{\circ} \mathrm{C}$. We must assume that we removed water randomly in our measurements in amounts comparable to those indicated by Yoshimuri et al. A difference of $24 \mathrm{~cm}^{2}$ in the surfaces of our two weights could therefore yield an uncertainty due to absorbed water up to $17 \mu \mathrm{g}$ (approximately our experimental uncertainty). Kochsiek [23] has made a study of the effect of moisture upon the mass of foils of various metals used in the fabrication of mass standards. He finds that for mechanically or electrolytically polished stainless steel the amount of water adsorbed on the surface is on the order of $0.1 \mu \mathrm{g} \mathrm{cm}^{-2}$ at 50 percent relative humidity, a result which is consistent with Yoshimuri's.

These results suggest that for more precise weighings, or for weighings at lower pressures than those described here, one would have to be very sure that the surfaces areas of the two weights were identical.

These measurements were sufficient to assure the weighings of any of our Faraday materials to within $0.8 \mathrm{ppm}$. We therefore carried the investigation no further.

\section{Conclusions.}

1. A convenient and inexpensive device can be constructed for the direct comparison of two masses in vacuum. The device consists of a vacuum chamber which can be weighed on a balance. We believe that the uncertainty in our measurements $(0.08 \%$ on the air density) can be reduced but physical and chemical evidence suggests that scrupulous care and perhaps chemical determination of surface moisture may be necessary for improvement of the results as much as tenfold.

2. Our experiments and that of Toropin and Snegov lead us to conclude further that the various similar air density algorithms are valid to within 0.08 percent. This in turn leads to the conclusion that a mass determination of the following materials will have at most the relative uncertainty indicated (due solely to the air density algorithm) starting from platinum-iridium standards: silver, $5 \times 10^{-8}$; stainless steel, $8 \times 10^{-8}$; water, $9 \times 10^{-7}$.

It may be concluded that our weighings of 1 molar perchloric acid (density $=1.05 \mathrm{~g} \mathrm{~cm}^{-3}$ ) and 4-aminopyridine (density $=1.27 \mathrm{~g} \mathrm{~cm}^{-3}$ ) described above have an uncertainty of no more than $0.9 \mathrm{ppm}$ from this cause.

3. These measurements show that the assignment of the mass unit from one kilogram to another can be made with an uncertainty attributable to the air density algorithm of no greater than $0.10 \mathrm{mg}$ per $100 \mathrm{~cm}^{3}$ in the volume difference of the kilograms.

The authors wish to thank P. E. Pontius for permission to use the apparatus in the Mass and Volume Section, NBS, and R. M. Schoonover for guiding us through the highprecision hydrostatic volume measurements on the stainless steel weights. The authors are also most grateful to S. Poet of the National Center for Atmospheric Research, Boulder, Colorado, and Prof. V. Ryan of the Chemistry Department, University of Wyoming, Laramie, for making available to us the facilities of those two laboratories.

The authors are particularly grateful to Harvey Diehl, Professor of Chemistry at Iowa State University at Ames. Professor Diehl suggested the approach to the solution of this problem and provided the hollow and stainless weights used in this study. Furthermore it was upon a brass prototype of his design that the vacuum enclosure in stainless steel was patterned. Professor Diehl is continuing his own study with the reasonable expectation of acquiring a precision several fold better than that reported here.

\section{References}

[1] W. F. Koch, H. Diehl: Talanta 23, (509), 1976.

[2] V. E. Bower, R. S. Davis: Atomic Masses and Fundamental Constants 5, J. H. Sanders, A. E. Wapstra, Eds. (Plenum Press New York 1976) pp 578-583.

[3] B. N. Taylor, W. H. Parker, D. N. Langenberg: The Fundamental Constants and Quantum Electrodynamics (Academic Press, New York, 1969).

[4] E. R. Cohen, B. N. Taylor: J. Phys. Chem. Ref. Data, 2, 663-734 (1973).

[5] Bureau International des Poids et Mesures, Sevres: Rapport, Reunion concernant les Masses, 23-24 Nov. 1976.

[6] G. P. Baxter: J. Am. Chem. Soc. 43, 1317-1318 (1921). 
[7] A. Jaquerod, C. Borel: J. Chem. Phys. 19, 11-28 (1921).

[8] H. A. Bowman, R. M. Schoonover, M. W. Jones: J. Res. Nat. Bur. Stand. (U.S.), 71C (Eng. and Instr.), No. 3, 179-198 (July-Sept. 1967).

[9] J. Brulmans, H. L. Eschbach: Rev. Sci. Instrum. 41, 1680 (1970).

[10] F. S. Acton, Analysis of the Straight Line, p. 36 (John Wiley and Sons, New York, 1959).

[11] W. Ferrel. Ann. Rep. Chief Signal Officer War Dept. Washington 1886 App 24, pp 233-259.

[12] S. Timoshenko. Theory of Plates and Shells (McGraw-Hill, New York 1940) pp 62 and 398.

[13] J. A. Goff, S. Gratch: Trans. Am. Soc. Heat. and Vent. Eng. 52, 125-164 (1946).

[14] Hyland, R. W., J. Res. Nat. Bur. Stand. (U.S.) 79A, (Phys. and Chem.) No. 4, 551-560 (July-Aug. 1975).
[15] Hyland, R. W., and Wexler, A., ibid. 77A (Phys. and Chem), No. 1, 133-147 (Jan.-Feb. 1973).

[16] R. J. List: Smithsonian Meteorological Tables 6 rev. ed. (Smithsonian Institution Press, Washington, 1949).

[17] F. E. Jones: J. Res. Nat. Bur. Stand. (U.S.), 83, No. 5, (Sept.-Oct. 1978).

[18] H. A. Bowman, NBS; Private Communication.

[19] R. M. Schoonover, NBS; Private Communication.

[20] S. E. Toropin, V. C. Snegov: Izmeritelnaya Tekhnika 12, 75, 1975. English translation; Meas. Tech. 1976, p. 1847.

[21] H. Moret, E. Louwerix: Vacuum Microbalance Techniques, Vol. 5, K. H. Behrendt, Ed. (Plenum Press, New York, 1966) pp 59-75.

[22] T. Yoshimori, S. Ishiwari, Y. Watanabe, T. Harada, S. Yamada: Trans. Jap. Inst. Metals. 14, 396-400 (1973).

[23] M. Kochsiek, PTB-Mitteilungen 87, 478-485, (1977). 